\title{
Presynaptic Morphological Changes Associated with Long-Term Synaptic Facilitation Are Triggered by Actin Polymerization at Preexisting Varicosities
}

\author{
Yohko Hatada, ${ }^{1,2}$ Fang Wu, ${ }^{2}$ Zhong-Yi Sun, ${ }^{2}$ Samuel Schacher, ${ }^{2}$ and Daniel J. Goldberg', ${ }^{1,2}$ \\ ${ }^{1}$ Department of Pharmacology and ${ }^{2}$ Center for Neurobiology and Behavior, Columbia University and New York State \\ Psychiatric Institute, New York, New York 10032
}

Morphological changes are thought to contribute to the expression of long-term synaptic plasticity, a cellular basis for learning and memory. The mechanisms mediating the initiation and maintenance of the morphological changes are poorly understood. We repeatedly imaged the axonal arbors of mechanosensory neurons of Aplysia as they formed new synaptic varicosities and axonal branches after applications of serotonin that cause long-term synaptic facilitation. New varicosities formed exclusively from preexisting varicosities, by splitting or branch outgrowth. These changes were prevented by cytocha- lasin D, which blocks actin polymerization and the turnover of actin filaments. The suppression of the morphological changes by cytochalasin D did not impair their expression when cytochalasin D was removed $24 \mathrm{hr}$ after exposure to serotonin. These results imply that serotonin induces persistent effects at preexisting presynaptic varicosities, which enhance actin polymerization, and that this is essential for presynaptic morphological changes of long-term facilitation.

Key words: Aplysia; actin; synapse; plasticity; long-term facilitation; varicosity
Long-term increases in synaptic transmission contribute to at least some types of learning and memory. The long-term increases in synaptic strength may be maintained by morphological change (Bailey and Kandel, 1993). For example, increases in the number of presynaptic varicosities and in the extent of the axonal arbor of the presynaptic neuron accompany long-term facilitation (LTF) at the synapse between the sensory neurons (SNs) and the motor neurons (L7) of the gill withdrawal reflex of Aplysia (Bailey and Chen, 1988; Glanzman et al., 1990). These morphological changes may be especially important for the maintenance of LTF for several days (Casadio et al., 1999). An increase in transmitter release contributes to the increase in efficacy of the SN-L7 synapse (Dale et al., 1988). Facilitation at this synapse has been an important model, both in the intact nervous system and in dissociated cell culture, for studying the molecular mechanisms underlying synaptic plasticity that contributes to learning (Alberini et al., 1995; Liu et al., 1997).

When isolated from the Aplysia CNS and placed together in culture, SN and L7 form a chemical synaptic connection, which resembles the connection in situ both electrophysiologically and morphologically (Rayport and Schacher, 1986; Glanzman et al., 1989). LTF and the increases in SN varicosities and axonal arbors that accompany it in situ can be produced in culture by transient applications of serotonin (5-HT) (Montarolo et al., 1986; Glanzman et al., 1990), a transmitter that contributes to LTF at this synapse in situ (Mackey et al., 1989). (LTF cannot be induced by electrical stimulation of the culture preparation.) The simple culture preparation has allowed certain experimental analyses that cannot presently be done in situ (Glanzman et al., 1990; Mayford et al., 1992; Sun and Schacher, 1998; Casadio et al., 1999).

The mechanisms mediating the initiation and maintenance of

Received Feb. 15, 2000; revised April 19, 2000; accepted April 24, 2000.

This work was supported by National Institutes of Health Grant NS36418 and National Science Foundation Grant 9808938. We thank Drs. E. Kandel, I. Kupfermann, and J. H. Schwartz for comments on an earlier version of this manuscript.

Correspondence should be addressed to Dr. Daniel J. Goldberg, Department of Pharmacology, Columbia University, 630 West 168th Street, New York, NY 10032. E-mail:djg5@columbia.edu.

Copyright $\odot 2000$ Society for Neuroscience $\quad 0270-6474 / 00 / 200001-\bullet \$ 15.00 / 0$ the morphological changes of long-term synaptic plasticity are poorly understood, partly because these changes have been difficult to follow over time in a living preparation. We have now been able to visualize presynaptic morphological changes as they occur during stimulation that produces LTF at this Aplysia synapse.

\section{MATERIALS AND METHODS}

Preparation of cultures and electrophysiological recordings. Each culture contained one SN plated near one L7 from the CNS of Aplysia californica (National Center for Research Resources, National Center for Aplysia, University of Miami, Miami, FL) and maintained for 5-7 d in hemolymph-supplemented medium (Rayport and Schacher, 1986). EPSPs were recorded before and $24 \mathrm{hr}$ after treatments, as described previously (Montarolo et al., 1986, 1988). After the first day, cultures were stored at $18^{\circ} \mathrm{C}$ in an incubator. Cultures were maintained at $18^{\circ} \mathrm{C}$ on the microscope stage during the entire period of time-lapse observation.

Facilitation protocol. Cultures were exposed five times, for $30 \mathrm{sec}$ each, to $20 \mu \mathrm{M} 5-\mathrm{HT}$ in the bath, with the exposures separated from each other by $10 \mathrm{~min}$. Electrophysiological recordings showed that this protocol caused LTF. Control cells were treated identically, but the vehicle (SL-15 culture medium without hemolymph) did not contain 5-HT.

Treatment with cytochalasin D. A stock solution of $5 \mathrm{~mm}$ cytochalasin $\mathrm{D}(\mathrm{CD})$ in DMSO was diluted in culture medium to the final desired concentration. Concentrations of 1-1500 nM were initially tested. One hundred nanomolar was the lowest concentration tested that completely blocked the morphological effects of 5-HT. CD was added 20 min before exposure to $5-\mathrm{HT}$ or vehicle and maintained for $24 \mathrm{hr}$. CD was then washed out, and cultures were left for another $24 \mathrm{hr}$ to assess reversibility of effects. Previous studies indicated that DMSO (0.1-0.2\%) has no effect

This article is published in The Journal of Neuroscience, Rapid Communications Section, which publishes brief, peer-reviewed papers online, not in print. Rapid Communications are posted online approximately one month earlier than they would appear if printed. They are listed in the Table of Contents of the next open issue of JNeurosci. Cite this article as: JNeurosci, 2000, 0: RC82 (1-5). The publication date is the date of posting online at www.jneurosci.org.

http://www.jneurosci.org/cgi/content/full/4307 
on steady-state synaptic transmission or the capacity of cultures to express LTF (Wu and Schacher, 1994).

Image acquisition. Individual SNs were stained with 1,1'-dioctadecyl$3,3,3^{\prime}, 3^{\prime}$-tetraindocarbocyanine perchlorate [DiI (C18)] as previously described (Hatada et al., 1999). DiI staining and cell imaging did not affect EPSP amplitude or the capacity of SNs to express LTF. Fluorescence and phase-contrast or differential interference contrast images were acquired digitally by using a cooled CCD camera with a $17 \times 17 \mathrm{~nm} /$ pixel chip (RTE/CCD-1317K2; Princeton Instruments, Trenton, NJ), with or without $2 \times 2$ binning. This was attached to an inverted light microscope (Eclipse TE200; Nikon, Melville, NY) with $20 \times[0.4$ numerical aperture (NA), plan] and $40 \times(1.3 \mathrm{NA}$, plan fluor) objective lenses.

Images were captured at focal planes separated by $2 \mu \mathrm{m}$ when the $20 \times$ objective was used and by $0.5 \mu \mathrm{m}$ when the $40 \times$ objective was used. A complete series of optical sections through the entire thickness $(\sim 10-20$ $\mu \mathrm{m}$ ) of the $\mathrm{L} 7$ axon (along which the $\mathrm{SN}$ axonal branches run) was captured every day starting the day before exposure to vehicle or 5-HT. For time-lapse studies, a series of optical slices covering $8 \mu \mathrm{m}$ was imaged every 10 or $20 \mathrm{~min}$ for the first $2 \mathrm{hr}$ after exposure and then every 1 or 2 hr. Two or three images, separated by $100 \mathrm{sec}$, were captured at each time to allow the visualization of rapid movements. We examined several adjacent optical sections to verify the overall dimensions of a varicosity. A varicosity was defined as an axonal swelling that, at its maximum diameter, was at least 1.5 times the thickness of the adjacent axon.

Measurement of neurite lengths was restricted to neurites growing on the underside of the motor axon, in contact with the substrate, so that we could simplify the analysis by viewing a single focal plane. Measurements of varicosity number and neurite length were restricted to sensory neurites in contact with the main motor axon stump, which often approached $1 \mathrm{~mm}$ in length, because only varicosities in contact with the stump have the active zones that define them as synaptic terminals (Glanzman et al., 1989, 1990; Schacher et al., 1990; Hatada et al., 1999). Previous studies quantitated only varicosity number; neurite length was formerly assessed only qualitatively (Glanzman et al., 1990; Sun and Schacher, 1998).

Statistical analysis. The significance of differences between mean values of the same groups of cells on the $2 \mathrm{~d}$ was assessed using a $t$ test for paired samples. The significance of differences between means of different groups of cells on an individual day was assessed by ANOVA followed by Bonferroni's modified $t$ test for multiple comparisons.

\section{RESULTS}

In previous studies of LTF at the SN-L7 synapse in culture, the morphology of the SN was viewed only once before facilitation and once $24 \mathrm{hr}$ after the induction of LTF, because the shortlived intracellular dye carboxyfluorescein was used (Glanzman et al., 1990; Sun and Schacher, 1998). We labeled the SN with DiI to be able to visualize its axonal arbor repeatedly and thereby track morphological changes as they initiated and developed (Hatada et al., 1999). The SN-L7 pair was maintained in culture for $5 \mathrm{~d}$ so that chemical synaptic connections were established and growth was reduced to a basal level (Montarolo et al., 1986; Glanzman et al., 1990).

Cells were exposed to 5-HT five times for $30 \mathrm{sec}$ each time. This transient treatment with 5-HT resulted $24 \mathrm{hr}$ later in significant increases in EPSP amplitude, the number of varicosities, and the extent of the axonal arbor. EPSP amplitude increased $56.3 \pm$ $12.6 \%$ (mean $\pm \mathrm{SEM} ; n=10)$, compared with $-1.1 \pm 3.9 \%(n=$ 11 ) in control cells (significantly different, $p<0.02$ ). The number of varicosities increased $58.9 \pm 11.8 \%(n=10)$ in the $24 \mathrm{hr}$ after exposure of cells to 5 -HT but only $22.5 \pm 6.9 \%(n=7)$ after exposure of control cells to vehicle (significantly different, $p<$ 0.02 ). There was a further $48.9 \pm 6.9 \%$ increase in the number of varicosities during the second $24 \mathrm{hr}$ after exposure to 5-HT compared with $8.9 \pm 4.0 \%$ in the control cells $(p<0.002)$. By 24 hr after 5-HT, there was an increase in the length of the SN axonal arbor of $42.4 \pm 2.2 \%(n=5)$ compared with $16.0 \pm 3.4 \%$ $(n=7)$ for control cells $(p<0.00005)$. Neurite length increased further during the second $24 \mathrm{hr}$ after 5 -HT but not by an amount significantly different from that seen in control cells.

We could unambiguously determine the mode of formation of 152 new varicosities. All formed as a result of morphological change originating at preexisting varicosities, although 5-HT was applied uniformly to the entire $\mathrm{SN}$, and varicosities constitute a small fraction of the length of the $\mathrm{SN}$ axonal arbor. We saw a spectrum of change: simple splitting of a varicosity, emergence from a varicosity of a short projection with a new varicosity at the end, and outgrowth from a varicosity of a substantial neuritic branch on which multiple varicosities formed (Fig. 1). Splitting of varicosities started within $1 \mathrm{hr}$ of exposure to 5-HT and continued throughout the period of observation. Outgrowth of new branches did not become evident for several hours. We never observed new branches growing from nonvaricose lengths of the axonal arbor. Splitting of varicosities occurred in control cells but 2.4 times less often than in cells exposed to 5-HT. Outgrowth of neurites from preexisting varicosities was a distinctive response to 5-HT and produced a somewhat more highly branched SN arbor; we never observed it in control cells, where growth resulted only from advance of preexisting growth cones. Only a minority (28\%) of the preexisting varicosities spawned new varicosities in response to 5-HT. This minority was not evidently distinct from other varicosities before exposure to 5-HT. Small and large, terminal and interstitial preexisting varicosities produced new varicosities (Fig. 1).

Detailed morphological analysis revealed small-scale and rapid dynamism in response to 5-HT. The outgrowth of axonal branches from varicosities was typically preceded by several hours by the emergence of short protrusions (Fig. 1c). Some new branches that grew out could be clearly seen to be tipped by growth cones with motile peripheral regions (Fig. $1 b$ ). The motile peripheral region of growth cones is invested with a rich network of actin filaments, which drives its formation and movements (Letourneau, 1983; Mitchison and Kirschner, 1988). These expressions of motility thus suggested that 5-HT was stimulating actin dynamics.

To assess the involvement of actin dynamics in the morphological changes induced by $5-\mathrm{HT}$, we used $\mathrm{CD}$, which blocks the polymerization of actin and the turnover of dynamic actin filaments (Cooper, 1987). Basal synaptic transmission and short-term facilitation elicited by 5-HT were not affected by CD (data not shown). CD was added to the bathing medium immediately before the exposure to vehicle or 5-HT and was maintained for 24 hr. One hundred nanomolar CD reduced the basal increases in control cells of varicosity number and neurite length, although only the latter was reduced significantly ( $p<0.05$; Fig. 2$)$, indicating that this basal growth depends on actin polymerization. The residual formation of varicosities in the presence of CD was attributable to conversion of terminal growth cones into varicosities. The effects of $C D$ were reversible. The increase in varicosity number in the $24 \mathrm{hr}$ after removal of CD (Fig. 2a, right gray bar) was considerably larger than control (Fig. $2 a$, right white bar), although not quite significantly so. It was more similar to the increase in varicosity number during the first $24 \mathrm{hr}$ for control cells (Fig. $2 a$, left white bar). The increase in neurite length in the $24 \mathrm{hr}$ after removal of CD (Fig. 2b, right gray bar) was also more similar to that seen in the first $24 \mathrm{hr}$ (Fig. $2 b$, left white bar) than in the second $24 \mathrm{hr}$ (Fig. 2b, right white bar) for control cells. These results would be expected if CD simply delayed growth $24 \mathrm{hr}$.

CD blocked all of the visible morphological responses to 5-HT. The emergence of small protrusions was blocked by $100 \mathrm{~nm} C D$. $\mathrm{CD}$ also blocked the increases in varicosity number $(p<0.0001)$ and axonal length $(p<0.00001)$ caused by 5-HT (Figs. 2, 3c). 5-HT elicited an LTF in the presence of CD $[35.1 \pm 10.2 \%(n=$ $17)$ vs $5.3 \pm 5.0 \%$ for $\mathrm{CD}$ alone $(n=7) ; p<0.05]$ that was somewhat less than the facilitation seen in the absence of $\mathrm{CD}$, but not significantly so. This is consistent with previous findings that increases in varicosity number are not required for the expression of LTF at 24 hr (Sun and Schacher, 1998; Casadio et al., 1999). The efficacies of preexisting varicosities might be increased by 5-HT to a greater or longer extent in the absence of new varicosities (e.g., by insertion of active zones normally destined for new varicosities; Davis et al., 1996; Stewart et al., 1996). However, LTF does not seem to persist as long (i.e., $72 \mathrm{hr}$ ) in the absence of increased varicosities (Casadio et al., 1999).

Morphological changes were expressed after washout of CD even without renewed application of 5-HT. After removal of CD, 

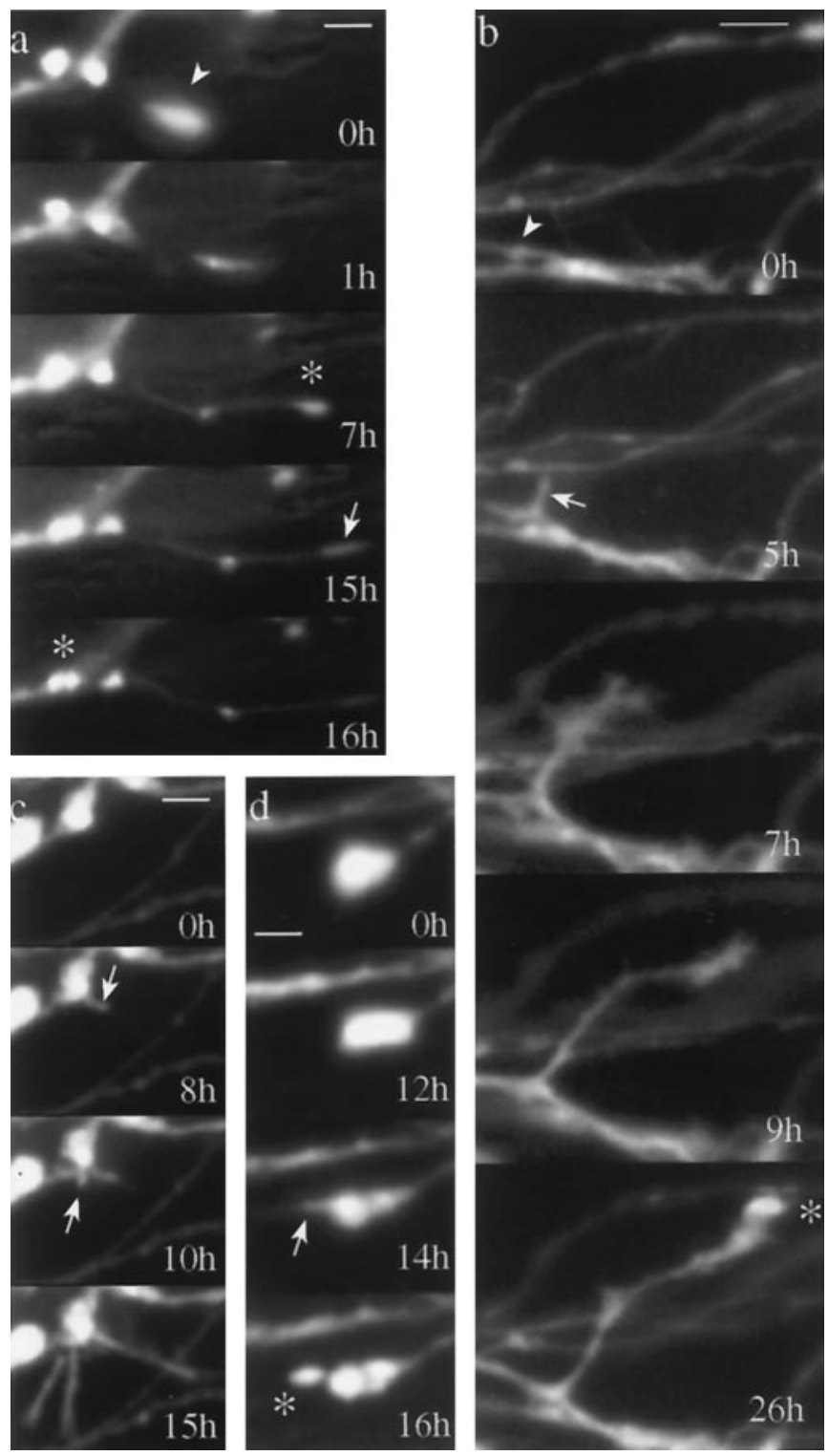

Figure 1. New varicosities form by splitting of preexisting varicosities or on axonal branches that grow out from preexisting varicosities. $a$, The leftmost varicosity has begun to split by $15 \mathrm{hr}$ after exposure to 5-HT and has split into two distinct varicosities by $16 \mathrm{hr}$ (asterisk). The rightmost varicosity, which is at the end of a branch, thins and elongates within $1 \mathrm{hr}$ of exposure to 5-HT. New growth, tipped by a new varicosity (asterisk), has extended several micrometers from the varicosity by $7 \mathrm{hr}$. After a time of quiescence, the growth resumes at $15 \mathrm{hr} . b$, A new branch (arrow) has begun to emerge from a preexisting internal varicosity (top panel, arrowhead) by 5 $\mathrm{hr}$ after exposure to 5-HT. At $7 \mathrm{hr}$ it displays a spread, motile growth cone. By $26 \mathrm{hr}$, it has stopped growing and formed a terminal varicosity (asterisk). $c$, By $8 \mathrm{hr}$ after exposure to 5-HT, a small protrusion (arrow) has emerged from an internal varicosity, and by $10 \mathrm{hr}$ a second (arrow) has emerged. There was little growth for the next few hours. Then there was a burst of growth resulting, at $15 \mathrm{hr}$, in three branches of several micrometers in length. $d$, By $12 \mathrm{hr}$ after application of 5-HT, a large varicosity is beginning to split. Subsequently, a protrusion emerges (arrow), which gives rise to a new small terminal varicosity (asterisk). Scale bars, $5 \mu \mathrm{m}$.

the amount of varicosity formation and axonal growth during the next $24 \mathrm{hr}$ (Fig. 2, 48 hr black bars) was similar to that seen in the first $24 \mathrm{hr}$ after exposure to 5-HT without CD (Fig. 2, $24 \mathrm{hr}$ striped bars). SNs that had been exposed to 5-HT showed more varicosity formation $(p<0.05)$ and axonal growth $(p<0.0001)$ in the 24 $\mathrm{hr}$ after removal of CD than in the previous $24 \mathrm{hr}$ in the presence of CD. Also, the increases in varicosity number $(p<0.01)$ and in

\section{a}
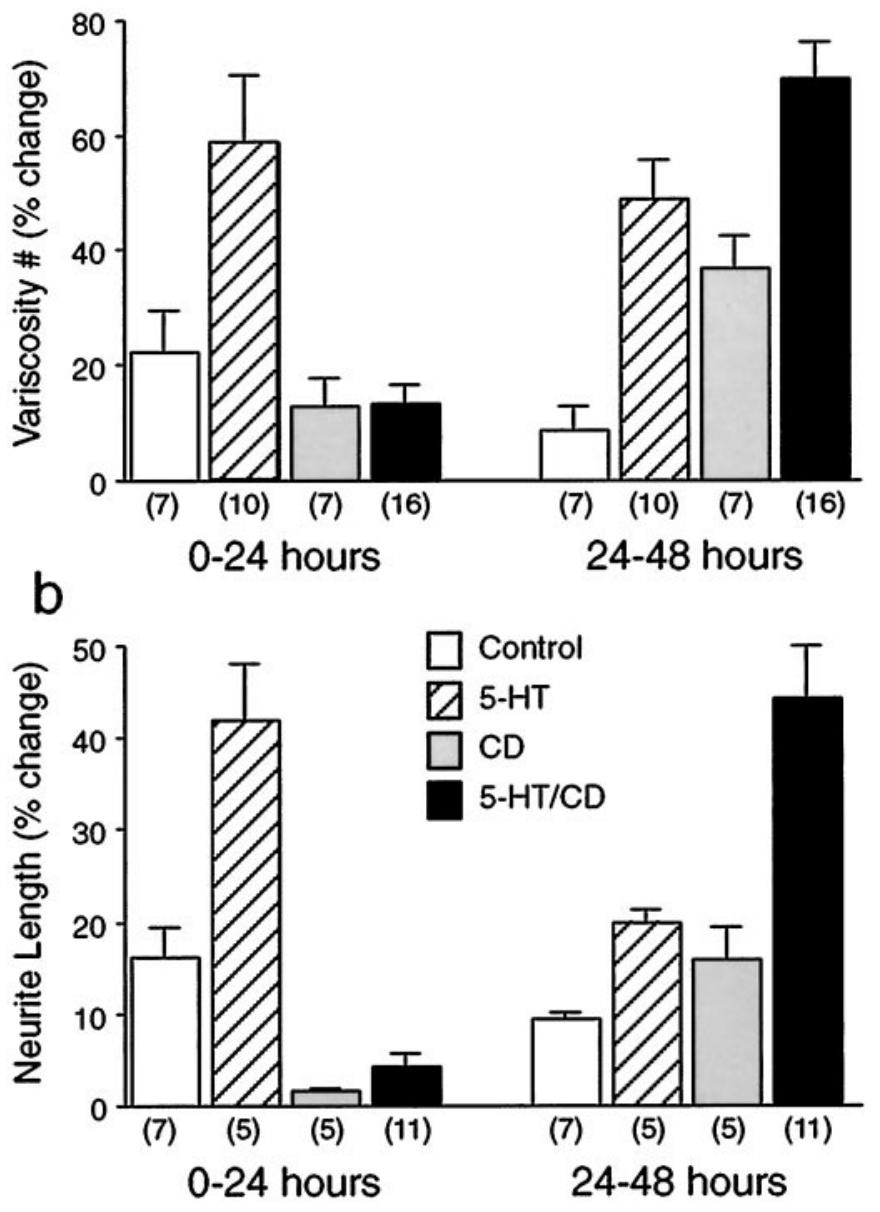

Figure 2. 5-HT causes changes in the number of SN varicosities $(a)$ and the length of the axonal arbors of SN $(b)$, which are blocked by CD. The left set of bars in $a$ and $b$ shows the mean \pm SEM percent increase for each treatment at $24 \mathrm{hr}$ after the start of treatment relative to immediately before treatment (number of cells in parentheses under each bar). The right set of bars shows the percent increase during the next $24 \mathrm{hr}$ ( $48 \mathrm{hr}$ time point relative to $24 \mathrm{hr}$ time point) for the same cells. CD was removed after $24 \mathrm{hr}$.

axonal length $(p<0.002)$ in the $24 \mathrm{hr}$ after the washout of $\mathrm{CD}$ were greater when 5-HT had been applied than when vehicle had been applied.

\section{DISCUSSION}

This is the first study in which presynaptic morphological changes have been viewed repeatedly as they initiate and develop during long-term synaptic plasticity. Visualization of the sequence of morphological changes has allowed us to identify their site of initiation. Frequent viewing of the same cell has allowed the detection of changes whose early onset, rapidity, or small magnitude would have made them undetectable by previous methods. The two major findings are that new varicosities of the presynaptic neuron result from morphological changes originating at preexisting varicosities and that these changes depend on actin polymerization.

\section{Morphological plasticity initiates at preexisting varicosities}

Previous work has shown by electron microscopy that the SN varicosities that form on the L7 axon in culture in response to repeated application of 5-HT have the active zones with clustered vesicles that define them (as well as can be done in Aplysia) as synaptic release sites (Glanzman et al., 1990; Schacher et al., 1990). We found here that, although 5-HT was applied uniformly 

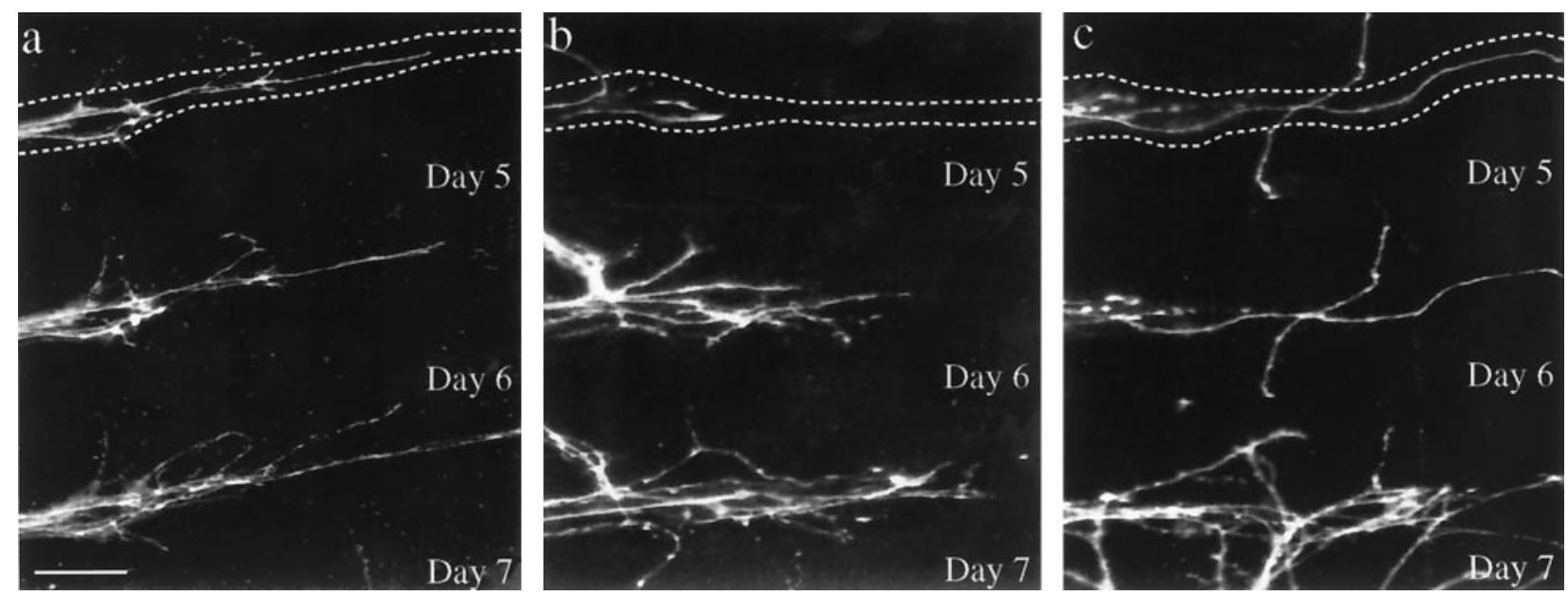

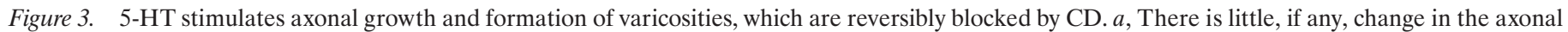

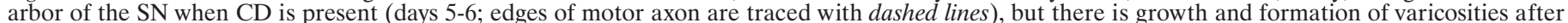

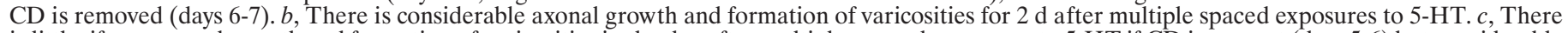

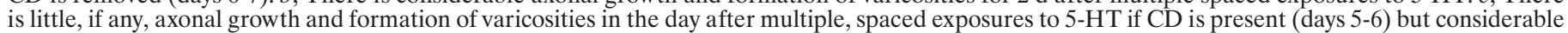

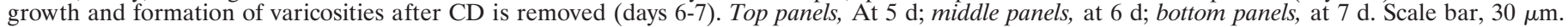

to the entire $\mathrm{SN}$, the morphological changes that resulted in the formation of these new synaptic varicosities occurred only at preexisting varicosities. This indicates that at least some of the preexisting SN varicosities are specialized to respond to 5-HT with growth. This is consistent with a previous finding that application of 5-HT to lengths of $\mathrm{SN}$ axons rich in varicosities produces short-term synaptic facilitation, whereas 5-HT applied to neighboring neurites lacking varicosities does not (Sun et al., 1996). Perhaps the 5-HT receptors that trigger electrophysiological and morphological change are concentrated at varicosities. Also, critical elements of the signal transduction pathway (such as protein kinases) or effectors of the morphological change (such as cytoskeletal proteins) might be enriched at varicosities. Another possibility is that, because 5-HT causes SN to form new varicosities and extend its axonal arbor only when L7 is in the culture with SN (Glanzman et al., 1990), the apposition of a postsynaptic specialization is critical.

Reduction of Aplysia cell adhesion molecule (ApCAM) on the surface of the SN has been suggested to be a key early event leading to the growth of new varicosities during LTF (Mayford et al., 1992; Zhu et al., 1995; Bailey et al., 1997). It has been hypothesized that this reduction removes a constraint on growth by fostering defasciculation of SN neurites from each other, with the defasciculated neurites then able to grow in contact with the motor axon and to form synaptic varicosities. Our results suggest that defasciculation mediated by ApCAM removal is not the initial trigger for growth. The initial morphological events we saw at varicosities did not apparently involve defasciculation. Also, ApCAM on the surface of the SN neurites decreases primarily at extravaricose sites; levels increase at preexisting varicosities (Zhu et al., 1995). Because we found that the morphological changes that give rise to new varicosities originated solely at preexisting varicosities, a downregulation of surface ApCAM seems not to be involved in triggering these changes. However, subsequent growth on the motor axon may be facilitated by the loss of ApCAM elsewhere on the SN neurites, as suggested previously (Mayford et al., 1992; Zhu et al., 1995; Bailey et al., 1997).

\section{Morphological changes are driven by actin dynamics}

We have identified actin as a molecular effector of presynaptic morphological changes accompanying LTF. Actin dynamics are high at the ends of many neurites growing and forming synapses during development (Mitchison and Kirschner, 1988). Thus, the growth of new synapses during plasticity in the adult CNS might involve a reawakening of actin dynamics in presynaptic neurons. But there has been no direct evidence for this idea, and it need not be true, because the outgrowth of new axonal arbor does not necessarily require conventional growth cones or the turnover of actin filaments. For example, elimination of actin-based motility with cytochalasin does not prevent growth of the Ti1 sensory axon within the developing grasshopper nervous system (Bentley and Toroian-Raymond, 1986). Formation and elongation of axons of rat hippocampal neurons in culture are actually facilitated by cytochalasin (Bradke and Dotti, 1999). Axonal arborization during development often occurs by the outgrowth of branches from regions of the axon well proximal to the leading growth cone, a process known as interstitial or back branching. Sometimes, the collateral branches do not appear to be tipped by the motile growth cones emblematic of actin-based motility (Harris et al., 1987; Bastmeyer and O'Leary, 1996; Wang and Macagno, 1997). Because interstitial branch growth was evident in the Aplysia SN in response to 5-HT but not in the basal growth seen without 5-HT, it was thus particularly interesting to see whether the 5-HT-induced growth required actin polymerization. We found that both the small-scale dynamism at varicosities and subsequent outgrowth of axonal branches elicited by 5-HT were completely blocked by a low concentration of CD. Thus, 5-HTinduced growth resembles the initial outgrowth of the $\mathrm{SN}$ axon in its dependence on actin polymerization. This is consistent with the idea that 5-HT is reawakening certain molecular pathways active during development.

Even when the 5-HT-induced effect on actin and the consequent morphological changes were completely suppressed by $\mathrm{CD}$ for $24 \mathrm{hr}$ after the application of 5-HT, they emerged after drug washout without further exposure to 5-HT. Thus, transient exposure to 5-HT induces a long-lasting change at preexisting synaptic varicosities, which underlies the actin-mediated effect. Increased cAMP activity and protein phosphorylation, which persist in the $\mathrm{SN}$ on this time scale after repeated exposures to 5-HT (Sweatt and Kandel, 1989; Müller and Carew, 1998), could be the important underlying changes. Elevated cAMP can elicit neuritic outgrowth from certain cells (Rydel and Greene, 1988) and can affect the actin cytoskeleton (Lamb et al., 1988). The stimulation by 5-HT of actin dynamics is likely just one of several changes that eventually cause axonal growth and the formation of varicosities, but it points to proteins involved in regulating actin polymeriza- 
tion and dynamics as potential targets in the varicosity for stimuli that induce synaptic plasticity.

\section{REFERENCES}

Alberini CM, Ghirardi M, Huang Y-Y, Nguyen PV, Kandel ER (1995) A molecular switch for the consolidation of long-term memory: cAMPinducible gene expression. Ann NY Acad Sci 758:261-286.

Bailey CH, Chen M (1988) Long-term memory in Aplysia modulates the total number of varicosities of single identified sensory neurons. Proc Natl Acad Sci USA 85:2373-2377.

Bailey CH, Kandel ER (1993) Structural changes accompanying memory storage. Annu Rev Physiol 55:397-426.

Bailey CH, Kaang BK, Chen M, Martin KC, Lim CS, Casadio A, Kandel ER (1997) Mutation in the phosphorylation sites of MAP kinase blocks learning-related internalization of apCAM in Aplysia sensory neurons. Neuron 18:913-924.

Bastmeyer M, O'Leary DDM (1996) Dynamics of target recognition by interstitial axon branching along developing cortical axons. J Neurosci $16: 1450-1459$

Bentley D, Toroian-Raymond A (1986) Disoriented pathfinding by pioneer neurone growth cones deprived of filopodia by cytochalasin treatment. Nature 323:712-715.

Bradke F, Dotti CG (1999) The role of local actin instability in axon formation. Science 283:1931-1934.

Casadio A, Martin KC, Giustetto M, Zhu H, Chen M, Bartsch D, Bailey CH, Kandel ER (1999) A transient, neuron-wide form of CREBmediated long-term facilitation can be stabilized at specific synapses by local protein synthesis. Cell 99:221-237.

Cooper JA (1987) Effects of cytochalasin and phalloidin on actin. J Cell Biol 105:1473-1478.

Dale N, Schacher S, Kandel ER (1988) Long-term facilitation in Aplysia involves increase in transmitter release. Science 239:282-285.

Davis GW, Schuster CM, Goodman CS (1996) Genetic dissection of structural and functional components of synaptic plasticity. III. CREB is necessary for presynaptic functional plasticity. Neuron 17:669-679.

Glanzman DL, Kandel ER, Schacher S (1989) Identified target motor neuron regulates neurite outgrowth and synapse formation of Aplysia sensory neurons in vitro. Neuron 3:441-450.

Glanzman DL, Kandel ER, Schacher S (1990) Target-dependent structural changes accompanying long-term synaptic facilitation in Aplysia neurons. Science 249:799-802.

Harris WA, Holt CE, Bonhoeffer F (1987) Retinal axons with and without their somata growing to and arborizing in the tectum of Xenopus embryos: a time-lapse video study of single fibres in vivo. Development 101:123-133.

Hatada Y, Wu F, Silverman R, Schacher S, Goldberg DJ (1999) En passant synaptic varicosities form directly from growth cones by transient cessation of growth cone advance but not of actin-based motility. J Neurobiol 41:242-251.

Lamb NJC, Fernandez A, Conti MA, Adelstein R, Glass DB, Welch WJ, Feramisco JR (1988) Regulation of actin microfilament integrity in living nonmuscle cells by the cAMP-dependent protein kinase and the myosin light chain kinase. J Cell Biol 106:1955-1971.
Letourneau PC (1983) Differences in the organization of actin in the growth cones compared with the neurites of cultured neurons from chick embryos. J Cell Biol 97:963-973.

Liu QR, Hattar S, Endo S, MacPhee K, Zhang H, Cleary LJ, Byrne JH, Eskin A (1997) A developmental gene (Tolloid/BMP-1) is regulated in Aplysia neurons by treatments that induce long-term sensitization. J Neurosci 17:755-764.

Mackey SL, Kandel ER, Hawkins RD (1989) Identified serotonergic neurons LCB1 and RCB1 in the cerebral ganglia of Aplysia produce presynaptic facilitation of siphon sensory neurons. J Neurosci 9:4227-4235.

Mayford M, Barzilai A, Keller F, Schacher S, Kandel ER (1992) Modulation of an NCAM-related adhesion molecule with long-term synaptic plasticity in Aplysia. Science 256:638-644.

Mitchison T, Kirschner M (1988) Cytoskeletal dynamics and nerve growth. Neuron 1:761-772.

Montarolo PG, Goelet P, Castellucci VF, Morgan J, Kandel ER, Schacher S (1986) A critical period of macromolecular synthesis in long-term heterosynaptic facilitation in Aplysia. Science 234:1249-1254.

Montarolo PG, Kandel ER, Schacher S (1988) Long-term heterosynaptic inhibition in Aplysia. Nature 333:171-174.

Müller U, Carew TJ (1998) Serotonin induces temporally and mechanistically distinct phases of persistent PKA activity in Aplysia sensory neurons. Neuron 21:1423-1434.

Rayport SG, Schacher S (1986) Synaptic plasticity in vitro: cell culture of identified Aplysia neurons mediating short-term habituation and sensitization. J Neurosci 6:759-763.

Rydel RE, Greene LA (1988) cAMP analogs promote survival and neurite outgrowth in cultures of rat sympathetic and sensory neurons independently of nerve growth factor. Proc Natl Acad Sci USA 85:1257-1261.

Schacher S, Glanzman D, Barzilai A, Dash P, Grant SG, Keller F, Mayford M, Kandel ER (1990) Long-term facilitation in Aplysia: persistent phosphorylation and structural changes. Cold Spring Harb Symp Quant Biol 55:187-202.

Stewart BA, Schuster CM, Goodman CS, Atwood HL (1996) Homeostasis of synaptic transmission in Drosophila with genetically altered nerve terminal morphology. J Neurosci 16:3877-3886.

Sun Z-Y, Schacher S (1998) Binding of serotonin to receptors at multiple sites is required for structural plasticity accompanying long-term facilitation of Aplysia sensorimotor synapses. J Neurosci 18:3991-4000.

Sun Z-Y, Kauderer B, Schacher S (1996) Differential distribution of functional receptors for neuromodulators evoking short-term heterosynaptic plasticity in Aplysia sensory neurons. J Neurosci 16:7540-7549.

Sweatt JD, Kandel ER (1989) Persistent and transcriptionallydependent increase in protein phosphorylation in long-term facilitation of Aplysia sensory neurons. Nature 339:51-54.

Wang H, Macagno ER (1997) The establishment of peripheral sensory arbors in the leech: In vivo time-lapse studies reveal a highly dynamic process. J Neurosci 17:2408-2419.

Wu F, Schacher S (1994) Pre- and postsynaptic changes mediated by two second messengers contribute to expression of Aplysia long-term heterosynaptic inhibition. Neuron 12:407-421.

Zhu H, Wu F, Schacher S (1995) Changes in expression and distribution of Aplysia cell adhesion molecules can influence synapse formation and elimination in vitro. J Neurosci 15:4173-4183. 